\title{
Effects of female urine on growth and sexual maturation in male rabbits
}

\author{
Diana J. Bell and Susan Mitchell \\ School of Biological Sciences, University of East Anglia, Norwich NR4 7TJ, U.K.
}

\begin{abstract}
Summary. Urine of adult males or adult females, or distilled water (control), was applied to the oro-nasal grooves of Dutch-belted male rabbits after weaning. The body and testicular weights of males treated with urine of females were significantly less than those of controls between 88 and 125, and 96 and 109 days, respectively. Sperm counts and the pattern of androgen-dependent production of gel-plugs in semen also differed significantly between treatments during the critical maturation period.

These suppressant effects of urine of females on male development in rabbits may represent a mechanism by which females may manipulate the reproductive success of neighbouring conspecifics in free-living colonies.
\end{abstract}

\section{Introduction}

In many mammals the onset of puberty may be accelerated or delayed by so-called 'primer' pheromone signals released by conspecifics. Much of this research has focussed upon the maturation-accelerating effects of urine of adult males on juvenile females in rodents (Vandenbergh, 1980; Carter, Getz, Gavish, McDermott \& Arnold, 1980; Baddaloo \& Clulow, 1981) although analogous effects have been reported in the pig and cow (Kirkwood, Forbes \& Hughes, 1981; Vandenbergh \& Izard, 1983). We have been exploring the possibility of similar physiological priming effects in European rabbits (Oryctolagus cuniculus) which also use pheromonal signals for communication (Mykytowycz, 1968; Bell, 1980; Bell \& Reece, 1983). The present study examined growth and sexual development in young male rabbits exposed to urine from adult male or female conspecifics.

\section{Materials and Methods}

Male rabbits of the Dutch-belted strain, bred from 12 litters at the University of East Anglia, were treated, from weaning at 45 days of age, with urine of adult males (Group MU), urine of adult females (Group FU) or distilled water (Group C, control). Siblings were allocated across treatments to give groups ( 9 rabbits in each) of equivalent body weight. The animals were housed in individual cages $(62 \times 52 \times 50 \mathrm{~cm}$ high) and provided ad libitum with rabbit growers pellets (Allen \& Page, Quayside Mills, Norwich), hay and water.

The $0.05-\mathrm{ml}$ doses of urine from adult males or adult females or distilled water were applied from a 1-ml syringe to the oro-nasal grooves of each rabbit for a total of 76 days (an average of 3-4 times a week) between 56 and 202 days of age. All urine administered had been pooled in equal volumes from 2 donors of the appropriate sex and was not more than $48 \mathrm{~h}$ old. One donor of each sex was replaced by a third, 1 month after the first urine treatment. No rabbit ever received urine from his mother. 
From 88 days of age regular estimates of paired testes weight were calculated for each animal by applying the formula derived by Paufler, Van Vleck \& Foote (1969) to calliper measures of testes lengths and widths.

To monitor the development of sexual behaviour, the response of individual males to a Waltontype artificial vagina (AV) hand-held inside a rabbit skin (Walton, 1958; Adams, 1972) was examined in a total of 18 home-cage tests per animal between 73 and 230 days of age. The temperature inside the AV was maintained at $40-45^{\circ} \mathrm{C}$ and the rubber lining was lubricated with soft white-paraffin jelly (Fisons, Loughborough, Leics). The first $11 \mathrm{AV}$ tests lasted $10 \mathrm{~min}$ or until first ejaculation. In the remaining 7 tests any male not ejaculating during the initial exposure of 2 min to the AV ('artificial' doe) received additional sexual stimulation in the form of a maximum of 10 min interactions with an oestrous 'teaser', Dutch-strain doe. Appropriate positioning of the AV between the 'teaser' doe and mounted male permitted collection of the first ejaculate produced during such tests. Any gel plug released in the ejaculate was removed before measuring the volume of semen and estimating the total number of spermatozoa present by using a haemocytometer. Appropriate non-parametric statistical tests were applied in the data analysis.

\section{Results}

One male in each group was found to be monorchid and so the data for these were excluded from all analyses of testicular function and sexual behaviour, leaving 8 males/group. The body weights (Text-fig. 1a) and testes weights (Text-fig. 1b) of Group FU males were significantly less than those of Group $C$ between 88 and 125 and 96 and 109 days, respectively. Males in Group MU did not differ significantly from those in Group $\mathrm{C}$ in terms of body or testes weights.

Treatment appeared to have no significant effect on the ages at which males first mounted and first ejaculated semen with or without motile spermatozoa, i.e. males in Groups C, MU and FU first mounted the 'artificial' or 'teaser' does at a mean \pm s.e.m. (8 rabbits/group) age of $101 \pm 9,122$ $\pm 11,105 \pm 12$ weeks (d.f. $=2, H=1.97$, N.S., Kruskal-Wallis test) and first ejaculated semen at $112 \pm 11,126 \pm 9$ and $122 \pm 12$ weeks respectively (d.f. $=2, \mathrm{H}=1 \cdot 00$, N.S., Kruskal-Wallis test).

Of the 12 males that had failed to mount the 'artificial' doe during tests $1-11,10$ mounted and ejaculated motile spermatozoa when first exposed to the oestrous 'teaser' doe in test 12 at 146 days of age, but still failed to show sexual mounting of the 'artificial' doe for several weeks (Text-fig. 2).

In each of Groups $\mathrm{C}, \mathrm{MU}$ and $\mathrm{FU}, 4 / 8$ diorchid males had ejaculated motile spermatozoa by 117,125 and 146 days of age respectively in response to the 'artificial' or live 'teaser' females and similarly by 117,125 and 201 days in response to the 'artificial' doe alone. The first 3 ages coincided with the attainment of a mean paired testes weight of $>3 \mathrm{~g}$ (i.e. $0 \cdot 17 \%$ intact body weight) after a period of rapid testicular growth (Text-fig. $1 \mathrm{~b}$ ). The numbers of males with testicular weights $\geqslant 3 \mathrm{~g}$ by 137 days of age varied significantly between treatments : 5/8 in Group C, 7/8 in Group MU and $2 / 8$ in Group FU. Results for Group C did not differ significantly from those for Groups MU and FU but the number of males with testicular weight $\geqslant 3 \mathrm{~g}$ in Groups MU and FU did differ significantly ( $P=0.04$, Fisher's Exact Test, two-tailed).

In view of the positive relationship between sperm output and weight of paired testes previously reported for rabbits (Amann \& Lambiase, 1967) one might expect to find relatively lower sperm counts in ejaculates collected from males with smaller testes. The mean total sperm count for Group FU males was lower than that in Groups $\mathrm{C}$ and MU in consecutive collections at 152, 160 and 187 days of age and the difference between Groups FU and MU was statistically significant at 160 days (Text-fig. 3).

The production of transparent gel plugs with semen also varied with treatment (Text-fig. 3). The total number of gel plugs produced during the $18 \mathrm{AV}$ tests was similar with mean \pm s.e.m. numbers/rabbit of $2 \cdot 3 \pm 0 \cdot 9,3 \cdot 0 \pm 0.9$ and $2 \cdot 4 \pm 0 \cdot 9$ for Groups $\mathrm{C}$, MU and FU respectively $(\mathrm{H}=$ $1 \cdot 24$, d.f. $=2$, N.S., Kruskal-Wallis test) but peak plug production occurred later in Group FU 

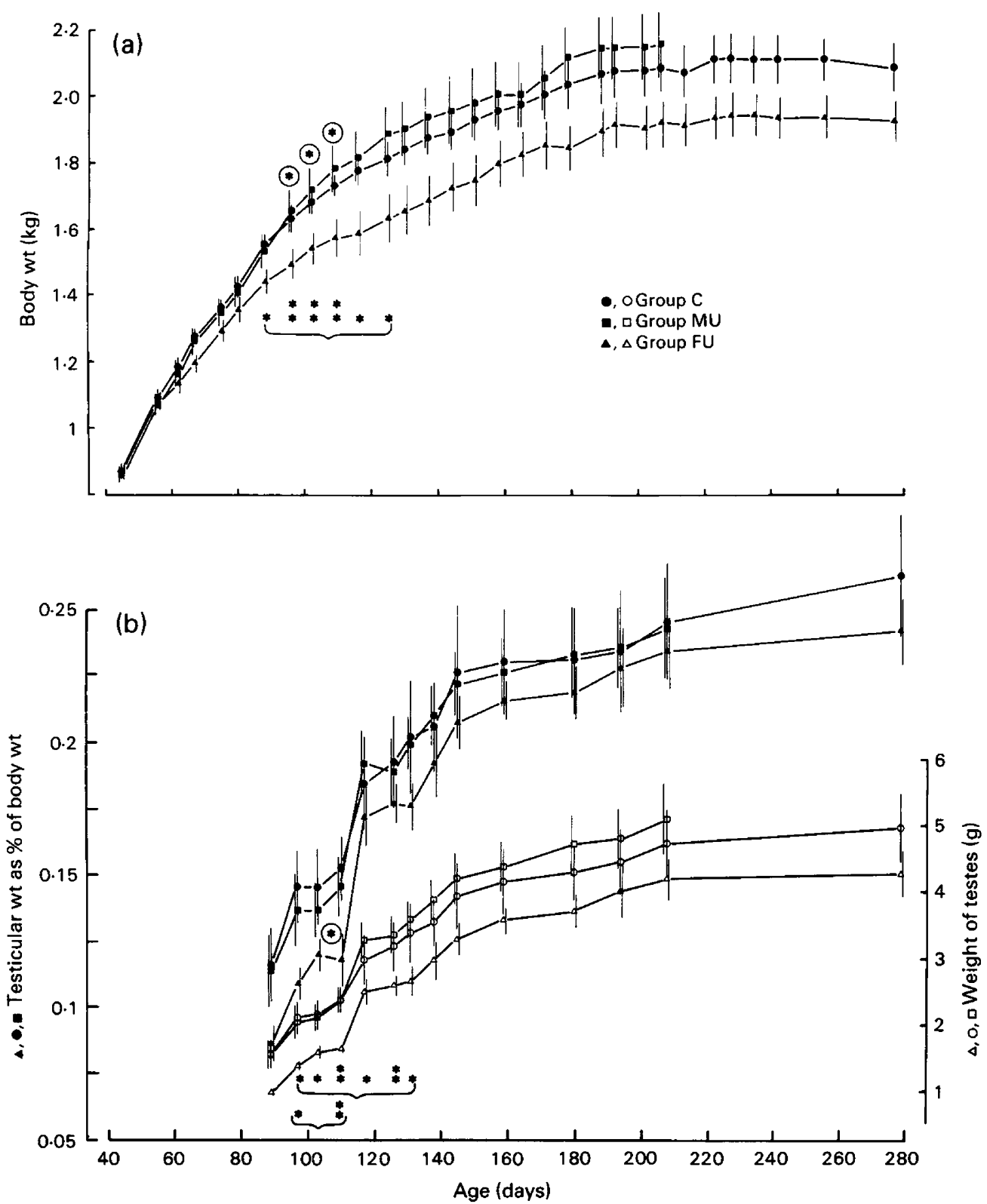

Text-fig. 1. Mean \pm s.e.m. body (a) and testicular (b) weights of male rabbits in Group C (distilled water), Group MU (adult male urine) or Group FU (adult female urine). In (a) the 3 groups differ significantly at 96,102 and 109 days of age $\left({ }^{*} P<0.05, \mathrm{Kruskal}-\mathrm{Wallis}\right.$ analysis of variance). Males in Group FU were significantly lighter than controls between 85 and 125 days $\left({ }^{*} P \leqslant 0.05, P \leqslant 0.02\right.$, two-tailed Mann-Whitney $U$ test $)$ when males had each received a total of 23 and 47 urine treatments respectively. The standard errors for the means in Group MU are shifted to the left of the symbol and those of the FU means to the right. $N=9$ in each group. In (b) the weight of paired testes per se varied significantly with treatment at 96 and 109 days of age $(P<0.05$ and $<0.02$ respectively, Kruskal-Wallis test). The testes of males in Group FU were significantly lighter than those of Group MU between 96 and 137 days and Group $C$ males at 96 and 103 days $\left({ }^{*} P \leqslant 0.05, * P \leqslant 0.02\right.$ derived from two-tailed MannWhitney $U$ test). Testicular weight expressed as a percentage of body weight also differed significantly in FU and MU males at 109 days of age $\left({ }^{*} P<0.05\right.$ two-tailed Mann-Whitney $U$ test). 


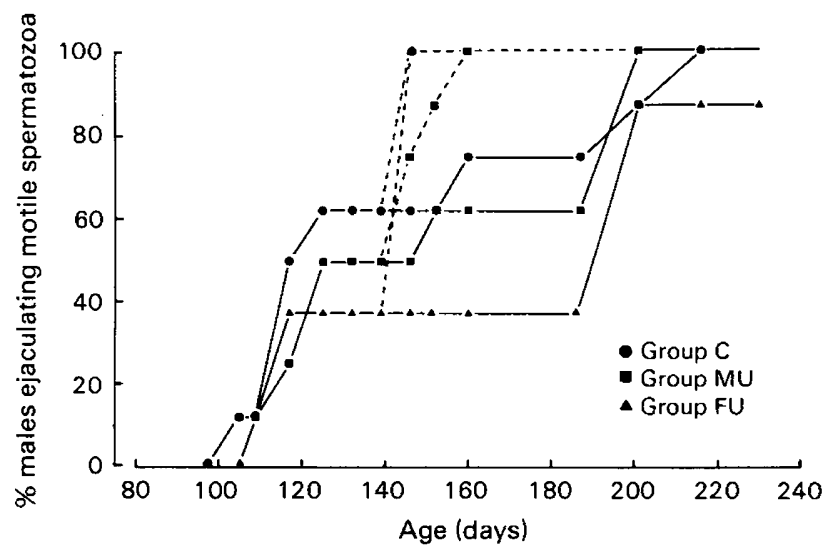

Text-fig. 2. Cumulative percentage of males ejaculating motile spermatozoa in successive tests with an 'artificial doe' alone (solid lines) or with additional stimulation from an oestrous 'teaser' doe (from 146 days-broken lines).

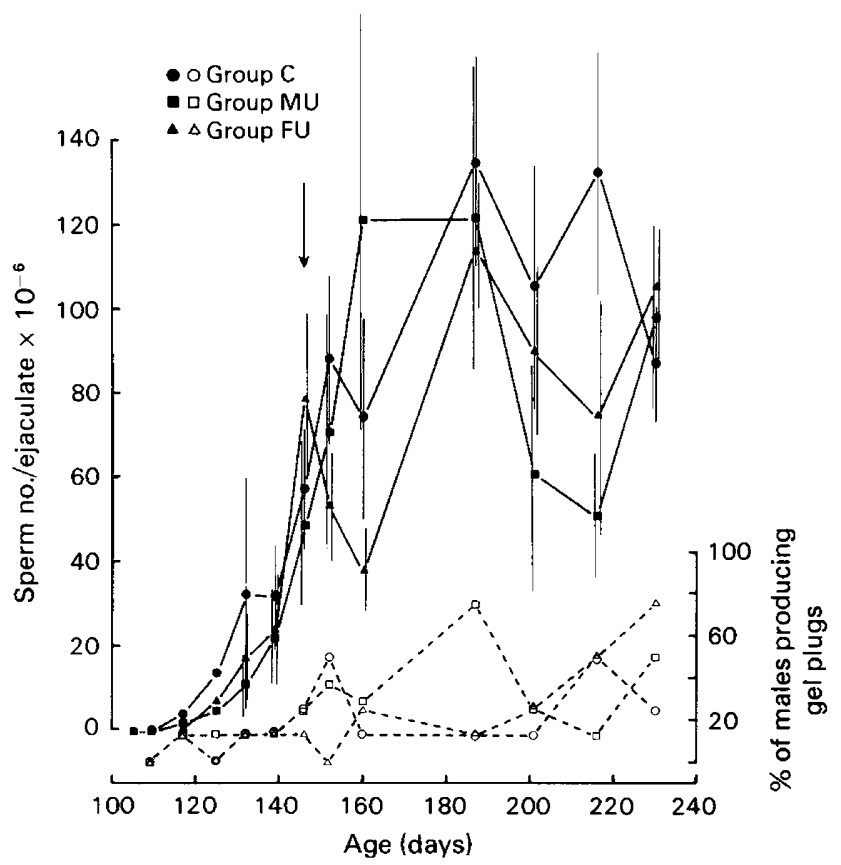

Text-fig. 3. Mean ( \pm s.e.m., 8 rabbits/group) sperm number/ejaculate (solid lines) and percentage of males producing a gel plug with semen (broken lines). Males in Group FU (N = 8 rabbits) produced significantly fewer spermatozoa than did those in Group $M U(N=7$, because one male ejaculated outside the AV) in ejaculates collected at 160 days of age $(U=11$, $P=0 \cdot 027$, one-tailed Mann-Whitney U-test). The arrow indicates the age at which males first received additional stimulation with a 'teaser' female if they failed to ejaculate in response to the 'artificial female' alone.

males than in Group C and MU males. For example, by test 16 at 201 days 2 or more plugs had been produced by $1 / 8,4 / 8$ and 6/8 males in Groups FU, C and MU respectively; the difference between Groups FU and MU is statistically significant ( $P=0 \cdot 04$, Fisher's Exact Test, two-tailed). 


\section{Discussion}

The age at which $50 \%$ of the control males were ejaculating motile spermatozoa in the present study (117 days) corresponds well with the age at which spermatozoa appeared in the testes (112 days) in an earlier histological study of testicular development in an unspecified strain of domestic rabbit (Leeson \& Leeson, 1970).

However, exposure to urine from adult female conspecifics after weaning appeared to suppress the development of young males during this critical maturation period and their body and testicular weights differed significantly from those of controls between 88 and 125 , and 96 and 109 days of age respectively. The significant difference between males in Groups FU and $\mathrm{MU}$ in testes weight expressed as a percentage of body weight at 109 days (Text-fig. 1b) may indicate additional suppression of gonadal development in the smaller males in Group FU. The differing pattern of gel plug production with semen found in the Group FU males may be taken as further evidence for inhibited gonadal functioning in these animals, since the production of this gelatinous component of rabbit semen appears to be androgen-dependent (Cheng \& Casida, 1949).

The broad fluctuations in the sperm concentrations of ejaculates collected from the same rabbit, noted during the present study, have been previously reported (Hafez, 1970). This variability is partly attributable to endogenous cycles of testicular activity in male rabbits in which the volume of semen and the number and motility of spermatozoa ejaculated fluctuate in concert in cycles of 2-7 days (Doggett, 1956).

The priming effects on juvenile males described here differ from those reported for rodents, in which male sexual development is accelerated by the presence of an adult female in mice (Fox, 1968; Vandenbergh, 1971) and inhibited by that of an adult male in mice and prairie deermice (Bediz \& Whitsett, 1979). In mice, brief exposure to urine of females elevates plasma LH levels in juvenile males (Maruniak, Coquelin \& Bronson, 1978) and in prairie deermice urine from adult males will suppress gonadal development in young males while urine of females has no significant effect (Lawton \& Whitsett, cited by Vandenbergh, 1980). Furthermore, and again in contrast to our findings with rabbits, these rodent suppressant effects were specific to gonadal development, with no apparent effects on body growth.

In mice, the puberty-accelerating 'pheromone' present in male urine has been identified as an androgen-dependent peptide with a molecular weight of around 860 (Vandenbergh, Finlayson, Dobrogosz, Dills \& Kost, 1976). In male rabbits growth and sexual function are suppressed after a single injection of 6-chloro-6-17-acetoxyprogesterone at 42 days of age (Skinner \& Adams, 1969), and this may be relevant when attempts are made to characterize the active component(s) in urine of female rabbits.

One may consider the possible adaptive significance of such a female suppressant effect of male maturation in wild rabbit populations, in which adults of both sexes are known to spray urine over young conspecifics (Bell, 1980). In high density rabbit populations the formation of separate dominance hierarchies between male and female members of the warren-based breeding groups serve to regulate the exploitation of limited resources so that the stronger individuals effectively maximize their own reproductive success by manipulating the reproductive activites of subordinates (Bell, 1983). Subordinate males, for example, are denied access to oestrous females and show inhibited gonadal development while subordinate does show similar stressinduced reproductive suppression, with dominant females also denying them access to prime breeding warrens (Mykytowycz \& Fullagar, 1973) and killing their young (Mykytowycz \& Dudzinski, 1972).

The typical pattern of juvenile dispersal found in this species seems to involve the enforced migration of sexually maturing males (Dunsmore, 1974). The suppressant effect on the development of 'strange' juvenile males reported here may therefore represent an additional mechanism by which females may manipulate the reproductive success of surrounding conspecifics. We are currently investigating whether maternal urine induces a similar response. 
We thank Dr Cyril Adams for training in the semen collection technique, and the S.E.R.C. for financial support.

\section{References}

Adams, C.E. (1972) The rabbit. In UFAW Handbook on the Care and Management of Laboratory Animals, 4th edn, pp. 172-192. Churchill-Livingstone, Edinburgh.

Amann, R.P. \& Lambiase, J.T. (1967) The male rabbit. 1. Changes in semen characteristics and sperm output between puberty and one year of age. J. Reprod. Fert. 14, 329-332.

Baddaloo, E.G.Y. \& Clulow, F.V. (1981) Effects of the male on growth, sexual maturation and ovulation of young female meadow voles, Microtus pennsylvanicus. Can. J. Zool. 59, 415-421.

Bediz, G.M. \& Whitsett, J.M. (1979) Social inhibition of sexual maturation in male prairie deermice. J. comp. Physiol. Psychol. 93, 493-500.

Bell, D.J. (1980) Social olfaction in lagomorphs. Symp. zool. Soc. Lond. 45, 141-163.

Bell, D.J. (1983) Mate choice in the European rabbit. In Mate Choice, pp. 211-223. Ed. P. P. G. Bateson. Cambridge University Press.

Bell, D.J. \& Reece, C. (1983) An investigation into the 'Bruce Effect' in domesticated rabbits. In Chemical Signals in Vertebrates, Vol. 3, pp. 339-342. Eds D. Muller-Schwarze \& R. M. Silverstein. Plenum Press, New York.

Carter, C.S., Getz, L.L., Gavish, L., McDermott, J.L. \& Amold, P. (1980) Male-related pheromones and the activation of female reproduction in the prairie vole (Microtus ochrogaster). Biol. Reprod. 23, 1038-1045.

Cheng, P. \& Casida, L.E. (1949) Effects of testosterone propionate upon sexual libido and the production of semen and sperm in the rabbit. Endocrinology 44, 3848.

Doggett, V.C. (1956) Periodicity in the fecundity of male rabbits. Am. J. Physiol. 187, 445-450.

Dunsmore, J.D. (1974) The rabbit in subalpine southeastern Australia. 1. Population structure and productivity. Aust. Wildl. Res. 1, 1-16.

Fox, K.A. (1968) Effects of prepubertal habitation conditions on the reproductive physiology of the male house mouse. J. Reprod. Fert. 17, 75-85.

Hafez, E.S.E. (1970) Rabbits. In Reproduction and Breeding Techniques for Laboratory Animals, pp. 273298. Ed. E. S. E. Hafez. Lea \& Febiger, Philadelphia.

Kirkwood, R.N., Forbes, J.M. \& Hughes, P.E. (1981) Influence of boar contact on attainment of puberty in gilts after removal of the olfactory bulbs. $J$. Reprod. Fert. 61, 193-196.

Leeson, C.R. \& Leeson, T.S. (1970) The postnatal development of the ductus epididymidis in the rabbit. Can. J. Zool. 48, 1147-1153.

Maruniak, J.A., Coquelin, A. \& Bronson, F.H. (1978) The release of $\mathrm{LH}$ in male mice in response to female urinary odors: characteristics of the response in young males. Biol. Reprod. 18, 251-255.

Mykytowycz, R. (1968) Territorial marking by rabbits. Sci. Amer. 218, 116-126.

Mykytowycz, R. \& Dudzinski, M.L. (1972) Aggressive and protective behaviour of adult rabbits, Oryctolagus cuniculus (L.) towards juveniles. Behaviour 43, 97120 .

Mykytowycz, R. \& Fullagar, P.J. (1973) Effects of social environment on reproduction in the rabbit, Oryctolagus cuniculus (L.). J. Reprod. Fert., Suppl. 19, 503-522.

Paufler, S.K., Van Vleck, L.D. \& Foote, R.H. (1969) Estimation of testicular size in the live rabbit. Int. $J$. Fert. 14, 188-191.

Skinner, J.D. \& Adams, C.E. (1969) Some effects of a single injection of chlormadinone acetate or methallibure on sexual function in the pubescent male animal. II. The rabbit. J. Reprod. Fert. 20, 105-110.

Vandenbergh, J.G. (1971) The influence of the social environment on sexual maturation in male mice. $J$. Reprod. Fert. 24, 383-390.

Vandenbergh, J.G. (1980) The influence of pheromones on puberty in rodents. In Chemical Signals in Vertebrates and Aquatic Animals, pp. 229-241. Eds D. Muller-Schwarze \& R. M. Silverstein. Plenum Press, New York.

Vandenbergh, J.G. \& Izard, M.K. (1983) Pheromonal control of the bovine ovarian cycle. In Chemical Signals in Vertebrates, Vol. 3, pp. 153-158. Eds D. Muller-Schwarze \& R. M. Silverstein. Plenum Press, New York.

Vandenbergh, J.G., Finlayson, J.S., Dobrogosz, W.J., Dills, S.S. \& Kost, T.A. (1976) Chromatographic separation of puberty accelerating pheromone from male mouse urine. Biol. Reprod. 15, 260-265.

Walton, A.J. (1958) Improvement in the design of an artificial vagina for the rabbit. J. Physiol., Lond. 143, 26-28.

Received 24 August 1983 